merely say that Mr. Lane (a senior Surgeon to St. Mary's Hospital) saw the patient once alone and several times with me, and that Dr. Sanderson (Lecturer on Medical Jurisprudence at St. Mary's School, and Physician to several large public charities) saw him twice, and both quite agreed in everything that was done. But that is really beside the question, the point being not the progress, but the origin of the disease, which I hold to have been the unnecessary introduction of irritants into the urinary passages, under the pretence of curing a disease which is purely imaginary.

Equally beside the question is the allegation of my rudeness to Dr. Venables. I am not acquainted with him. Dr. Dawson named him, and I bowed; again I bowed to both as courteously as I could, when Dr. Dawson said he should "leave the patient in my hands." Dr. Venables said nothing to me, nor I to him. I will not discuss the point whether such conduct is "offensive" or not.

Again Dr. Dawson tries to annoy me by an irrelevant stalement that Mr. S- had not sent for me. This is simply untrae. He had written that morning, begging me to come, and his mother had posted the letter.

He also introduces an impertinent remark about my being laid up in bed with lumbago, and suggests that this caused me to neglect the patient. He knows from the date of my note that this temporary illness came on after the post-mortem examination, at which $\mathrm{I}$ assisted.

He also complains of my not taking any notice of his diagnosis, or guiding my treatment by it. As I am here using documentary evidence only, I will not quote any spoken words of his which made me think not highly of his scientific acquirements; but I will merely refer (first) to his printed letter in TrE LANCET, in which he speaks of the presence of "phosphate of lime" in the urine as an evidence of disease, though every student knows it to be the most universal normal constituent; and (secondly) to a carefully written and twice copied letter to me, in which he spells the optical instrument he professes to employ ("mycroscope") with a $y$-a presumptive proof, at least, of no great familiarity with it. These and many similar complaints really do not require a serious refutation: I must leave them to refute themselves now, for I fear your readers will tire of this long letter. But I trust they will bear with me one minute more while I explain my reasons for having brought forward this case, and why I think the matter one of prime importance :-

1. I believe so-called "spermatorrhoea" to be a purely im. ginary disease.

2. On the one hand, semen is, in many persons, secreted in large quantities, and may be found frequently in the urine without in the slightest degree injuring the health. It goes on for years unobserved and unknown, unless the mind is unfortunately infected with the notion that it is an important and morbid secretion.

3. On the other hand, the symptoms which are assigned in special books to "spermatorrhoa" are the symptoms of other disorders, a few of which I mentioned in my lecture, and which are traceable partly to the mind, and partly to the digestive organs.

4. Obviously, therefore, the treatment of these cases by local applications of instruments is useless, pernicious to health, and dangerous to life.

5. And, where the medical man has had the opportunity of learning better, it is dishonest and derogatory to the character of our profession.

6. Also, it is derogatory to the profession to circulate books which assume to describe this imaginary disease by attributing to it the symptoms of other diseases, and especially to circulate them amongst non-professional persons. That Dr. Dawson does this, I have documentary evidence, independent of the book found in poor Mr. S—'s drawer "with the author's compliments."

Believing that the profession at large will feel equally with myself an "animus" against such practices,

I am, Sir, your obedient servant,

Thos K. Chambers, M.D.

22B, Brook-street, Grosvenor-square, June 26th, 1861 .

\section{ACCIDENTAL POISONING.}

To the Editor of The Lancet.

Sir,-As Mr. Hills and myself were the medical attendants upon Mrs. Peel (the wife of the Dean of Worcester), we are enabled to furnish the particulars of her case, believing they may be of interest to many of your numerous readers.
On Sunday, June 16th, at five minutes to nine A.M., we were summoned to Mrs. Peel, who had taken by mistake laudanum instead of an aperient draught, which she was in the habit of taking occasionally. Upon my arrival about five minutes past nine A.M., I found the lady quite sensible, and enabled to give me a connected account of the accident. Two two-ounce white glass bottles were shown me. One contained a brown-coloured aperient draught, the other had contained the laudanum, so that the bottles would appear precisely similar in size, shape, and colour, an ordinary label merely distinguishing them from each other. These bottles were sent out by a chemist at Worcester. A small quantity of the laudanum had been used the previons night as an outward application, so that the quantity actually swallowed was about an ounce and a half. This had been taken at twenty minutes to nine A.M. upon an empty stomach. The mistake was immediately discovered, and the servants summoned for assistance. There happened to be a medical gentleman staying at the hotel, and to him they applied to know what would be the best antidote. That gentleman recommended mustard and coffee, but did not see our patient, as he was in his bath. The mustard and coffee were given as directed, but no vomiting followed until I had administered half a drachm of sulphate of zinc in a tumblerful of warm water, which instantly acted as an emetic, and this effect was again excited every few minutes by repeated doses of sulphate of zinc and copious draughts of warm water. The stomach-pump was also used ; but partly owing to the age of our patient (sixty-five), and partly from the existence of cardiac and hepatic disease, the efforts of vomiting, and more especially the introduction of the tube into the stomach, had nearly caused fatal syncope two or three times. Notwithstanding these unfavourable complications, our efforts were not relaxed until all smell of the poison had disappeared from the ejected fluids. A little coffee and brandy were then pumped into the stomach.

About this time (an hour after the accident) Mrs. Peel com plained of giddiness in the head; the eyelids closed; the pupils became contracted, and sleep came on. The usual treatment was then adopted. Our patient was kept awake, first, by walking her about; but the muscles soon became so relaxed, and the circulation and respiration so feeble, that other remedies had to be had recourse to, such as galvanism, mustard poultices to the spine, over the region of the heart, and calves of the legs, sprinkling the face with water, ammonia to the nostrils, tickling the soles of the feet and palms of the hands with a hair-brush, and injections into the rectum of beef-tea and brandy, the room being kept freely ventilated. In this way twelve hours passed over, and now the patient, showing signs of consciousness when roused, was allowed a little rest, as great prostration of the vital powers supervened. Very little nourishment could be swallowed, and so the rectum was again called upon to absorb stimulating nutriment; but several times during the night death seemed inevitable, apparently from the shock to the nervous system. Early in the morning a turpentine enema was given, which not acting after a few hours was repeated but without the desired effect. At the suggestion of Mr. Hills, Dr. Page was sent for on Monday, and that gentleman held consultations with us daily. As regards our general treatment, I may sum it up by observing that our object was to avoid excessive reaction by relieving the circulation, and to keep up the flagging powers of life, and that this plan was successful is proved by the fact that Mrs. Peel is now convalescent.

I think in this case it is remarkable-considering the large quantity of opium which must have been absorbed into the system, Mrs. Peel not being in the habit of taking anodynes, her age, and state of health-that recovery from its effects should have taken place ; and I think that if unfortunately fatal syncope had occurred during our treatment, we should have been justified in the course we adopted.

In conclusion, I would remind your non-professional readers that after an accidental dose of poison has been taken, one or two tumblerfuls of soap-suds and water, and tickling the throat, will be a safe and effectual remedy before medical assistance can be obtained.

Castle-terrace, Richmoud, June, 1861. Thomas Durcan, M. D.

\section{THE LATE OPERATIONS BY MR. SYME AT THE ROYAL INFIRMARY, EDINBURGH. To the Editor of THe LaNcet.}

SIR,-With reference to what was said in your last week's LANCET concerning the ligature of the internal iliac artery by Mr. Syme, I beg leave to mention that the ligature was de. 